\title{
Sonography in Childhood and Adolescence for General Radiologists - More Possibilities Than Expected...
}

\section{Sonografie im Kindes- und Jugendalter für AllgemeinradiologInnen - mehr Möglichkeiten als gedacht...}

Authors

Matthias Cornelius Schaal' ${ }^{1}$, Jörg Detlev Moritz ${ }^{2,3,4}$, Hans-Joachim Mentzel ${ }^{5,6}$, Meinrad Beer ${ }^{1}$

Affiliations

1 Abteilung für Diagnostische und Interventionelle Radiologie, University Ulm Medical Centre, Ulm, Germany

2 Radiology and Neuroradiology, University Hospital Schleswig-Holstein - Campus Kiel, Germany

3 Stellv. Leiter Sektion Pädiatrie, DEGUM Deutsche Gesellschaft für Ultraschall in der Medizin, Berlin, Germany

4 Vorstand AG Pädiatrische Radiologie, DRG - Deutsche Röntgengesellschaft, Berlin, Germany

5 Pädiatrische Radiologie, Institut für Diagnostische und Interventionelle Radiologie, Jena, Germany

6 Präsident, Gesellschaft für Pädiatrische Radiologie, Berlin, Germany

Key words

pediatric, ultrasound, thorax, abdomen, CNS, musculosketetal

received 23.02.2021

accepted 07.10.2021

published online 28.12.2021

Bibliography

Fortschr Röntgenstr 2022; 194: 521-531

DOI 10.1055/a-1681-2136

ISSN 1438-9029

(C) 2021. Thieme. All rights reserved.

Georg Thieme Verlag KG, Rüdigerstraße 14,

70469 Stuttgart, Germany

Correspondence

Dr. Matthias Cornelius Schaal

Department of Diagnostic and Interventional Radiology, University Hospital Ulm, Albert Einstein Allee 23, 89070 Ulm, Germany

Tel.: +49/7 31/50061001

Matthias.Schaal@uniklinik-ulm.de

\section{ABSTRACT}

Sonography is the most common imaging modality in childhood and adolescence. The rapid availability, absence of X-rays, bedside applicability, e. $g$. , in intensive care units, the lack of need for sedation, and last but not least the very good ultrasound conditions in the vast majority of cases are the main advantages of sonography. Due to the spectrum of patients, from premature infants to adolescents, a great variety of questions arise for the examiner. This requires knowledge of the various disease patterns in the different age groups. Proper handling of the young patients as well as their parents is essential in order to make the examination conditions as optimal as possible. Due to the smaller body size compared to adults, sonographic examinations of the abdomen and thorax in children and adolescents are usually possible with very good image quality. In the majority of cases, a definitive diagnosis is made by sonography without additional cross-sectional imaging, which is more common in adults. Due to the acoustic windows provided by the still open fontanelles, excellent image quality of the central nervous system is usually possible in the first year of life. In most cases, complex MRI examinations are not necessary. Due to the partly still missing ossification of the bony structures, further acoustic windows are available, which allow an examination of, e. g., the spinal canal. Ultrasound also plays a major role in the examination of soft tissues and the musculoskeletal system in childhood and adolescence, not only in hip ultrasound. The aim of this article is to show this very broad spectrum for colleagues working predominantly in adult radiology, to highlight some representative examples and to present the respective clinical features in childhood and adolescence.

Key Points:

- Ultrasound is the most important initial imaging modality in children and adolescents.

- Often, no further cross-sectional imaging is necessary.

- The most important area of application is the abdomen and pelvis.

- Furthermore, there are additional special applications such as CNS in neonates and infants, thorax, musculoskeletal system.

\section{Citation Format}

- Schaal MC, Moritz JD, Mentzel H et al. Sonography in Childhood and Adolescence for General Radiologists More Possibilities Than Expected.... Fortschr Röntgenstr 2022; 194: 521-531

\section{ZUSAMMENFASSUNG}

Die Sonografie stellt die häufigste Bildgebungsmodalität im Kindes- und Jugendalter dar. Die schnelle Verfügbarkeit, fehlende Röntgenstrahlung, bettseitige Anwendbarkeit z. B. auf 
der Intensivstation, die fehlende Notwendigkeit einer Sedierung und nicht zuletzt die in den allermeisten Fällen sehr guten Ultraschallbedingungen machen die wesentlichen Vorteile der Sonografie aus. Aufgrund des Patientenspektrums vom Frühgeborenen bis zum Jugendlichen ergibt sich eine große Vielfalt an Fragestellungen an den Untersucher. Dies erfordert die Kenntnis der verschiedenen Krankheitsbilder in den unterschiedlichen Altersstufen. Der richtige Umgang mit den kleinen Patienten und nicht zuletzt mit deren Eltern ist essenziell, um die Untersuchungsbedingungen so optimal wie möglich zu gestalten. Aufgrund der im Vergleich zu Erwachsenen geringeren Körpergröße sind sonografische Untersuchungen des Abdomens und des Thorax bei Kindern und Jugendlichen meist mit sehr guter Bildqualität möglich. In der Mehrzahl der Fälle wird mittels Sonographie die definitive Diagnose gestellt ohne Hinzunahme weiterer
Schnittbilddiagnostik, wie bei Erwachsenen eher üblich. Aufgrund der Schallfenster durch die noch offenen Fontanellen ist im ersten Lebensjahr eine meist exzellente Bildqualität auch bezüglich des ZNS möglich. Zumeist kann auf aufwendige MRT-Untersuchungen verzichtet werden. Aufgrund der teils noch fehlenden Ossifikation der knöchernen Strukturen ergeben sich weitere akustische Fenster, die eine Untersuchung z. B. des Spinalkanals ermöglichen. Der Ultraschall spielt auch bei der Untersuchung der Weichteile und des Bewegungsapparates im Kindes- und Jugendalter eine große Rolle, nicht nur bei der Hüftsonografie. Ziel des vorliegenden Artikels ist es, dieses sehr breite Spektrum für überwiegend in der Erwachsenenradiologie tätige Kolleginnen und Kollegen aufzuzeigen, einige repräsentative Beispiele hervorzuheben und die jeweiligen klinischen Besonderheiten im Kindes- und Jugendalter darzustellen.

\section{Introduction}

Sonography in childhood and adolescence is performed by pediatricians, pediatric surgeons and (pediatric) radiologists. Radiologists not specialized in pediatric radiology are more familiar with emergency examinations of small children and school children, but they rarely examine newborns and infants. The goal of the present article is to show the broad spectrum of possibilities for using sonography in children and adolescents and to provide detailed information using some typical disease patterns as examples. The present manuscript is not intended as a scientific paper or systematic literature research and makes no claim of completeness. Rather, the manuscript presents our own experiences based on a brief examination description and images of some typical diseases.

In addition to the generally known indications for sonographic examination of the upper abdominal organs, the gastrointestinal tract, the urogenital tract, the thyroid, soft tissues, and blood vessels, there is a very broad examination spectrum in newborns and infants due to the suitable acoustic windows. Examination conditions that are suitable for children are essential in pediatric sonography. Examinations should be performed in a relaxed and quiet atmosphere after first becoming acquainted with the child. The parents are included in the examination to help calm the child. In the case of newborns and infants, a heating lamp should be used to ensure that the child does not become chilled. A happy, satiated infant will often fall asleep during the examination. Warmed ultrasound gel is generally used. The examination time should be as short as possible, particularly in the case of uncooperative children. A video clip can be played on a monitor or the parents' phone for distraction. The diagnostic value of sonography can be limited in the case of infants and small children who are uncooperative or suffering from meteorism.

\section{Thorax and abdomen}

Chest and abdominal examinations in small children, school children, and adolescents are performed as in adults with a curved array transducer at the highest frequency possible depending on the patient's body type (1-9 MHz). High-frequency linear probes $(5-20 \mathrm{MHz})$ are used in infants and when examining the bowel and superficial structures.

Due to the brevity of this article, echocardiography cannot be discussed here.

Opacifications on the X-ray image like pleural effusion or enlargement of the mediastinum must often be differentiated and quantified. In the case of pneumonia, sonography is used to detect or rule out pleural effusion or empyema ( $\triangleright$ Fig. 1a). In the case of processes adjacent to the pleura, infiltrates can be detected [1] and monitored sonographically ( $\vee$ Fig. 1c, d). Contrastenhanced (CEUS) can be used off-label in empyema or abscesses. Ultrasound also has high diagnostic accuracy for the diagnosis of pneumothorax in preterm and term infants [2].

In the case of mediastinal masses (e. g., lymphomas, teratomas, cysts, duplicatures, or neuroblastomas), ultrasound can be useful for initial imaging. MRI or CT is often indicated as an additional imaging modality depending on clinical urgency and suspicion ( $\triangleright$ Fig. 2a, b). However, the thymus as a solid homogeneous formation with multiple small hyperechoic internal echoes can be easily sonographically differentiated from real tumors in the anterior upper mediastinum in newborns and infants ( $\triangleright$ Fig. 2c).

In children with an elevated diaphragm, diaphragmatic motility can be evaluated on the moving ultrasound image and documented in M-mode ( $\triangleright$ Fig. 1b). Lateral or subcostal access is used and the liver or the fluid-filled stomach serves as the acoustic window.

In children and adolescents, ultrasound is the primary method used for the diagnostic workup of acute abdominal pain. Further imaging is typically not necessary. In addition to an enlarged diameter of the appendix (>6 mm) with wall thickening, the criteria of acute appendicitis include hyperperfusion of the wall 

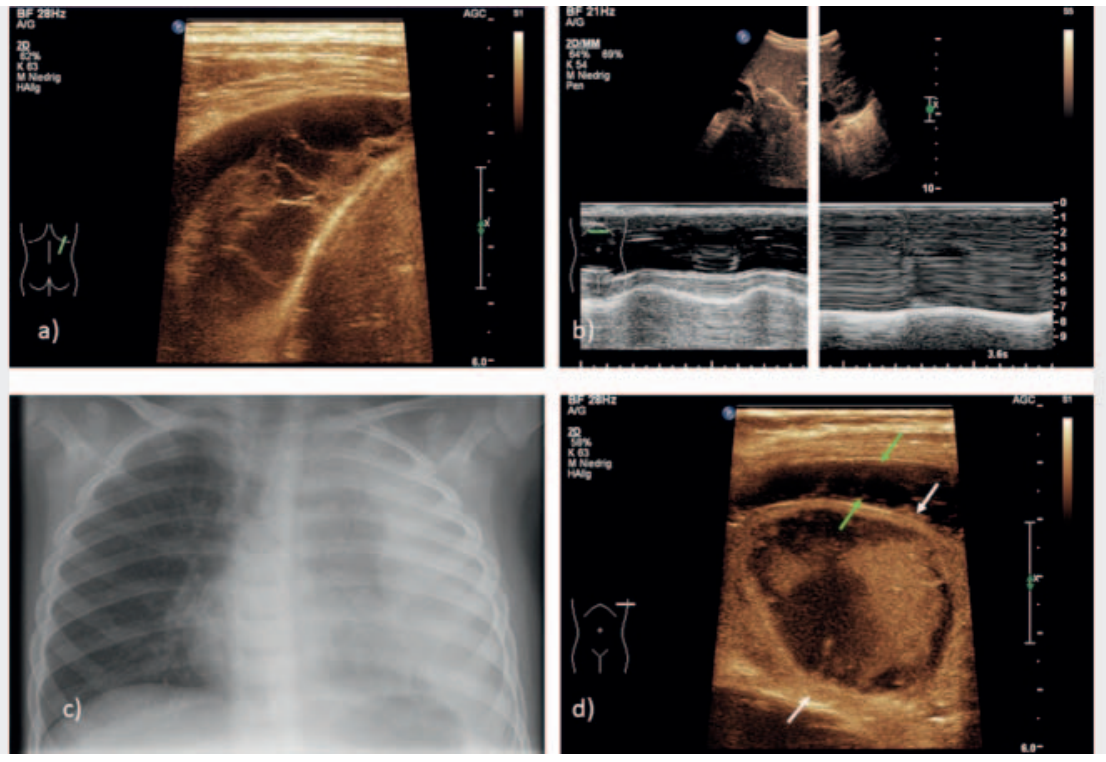

- Fig. 1 a Pleural empyema in a school child with complicated pneumonia, evidence of a fibrinopurulent effusion above the right diaphragm with multiple internal septa and internal echoes. b Absent diaphragmatic motility in M-mode (right half of image) in a newborn with unilateral diaphragmatic paresis; on the opposite side, normal diaphragmatic motility (left half of image). c Subtotal opacification of the left lung in chest X-ray in a child with history of fever, reduced general condition, and coughing. $\mathbf{d}$ Same child as in $1 \mathrm{c}$, sonographic detection of a large lung abscess (arrows) within the left lobe, necrotizing pneumonia. Additionally pleural effusion with few septations (green arrows).
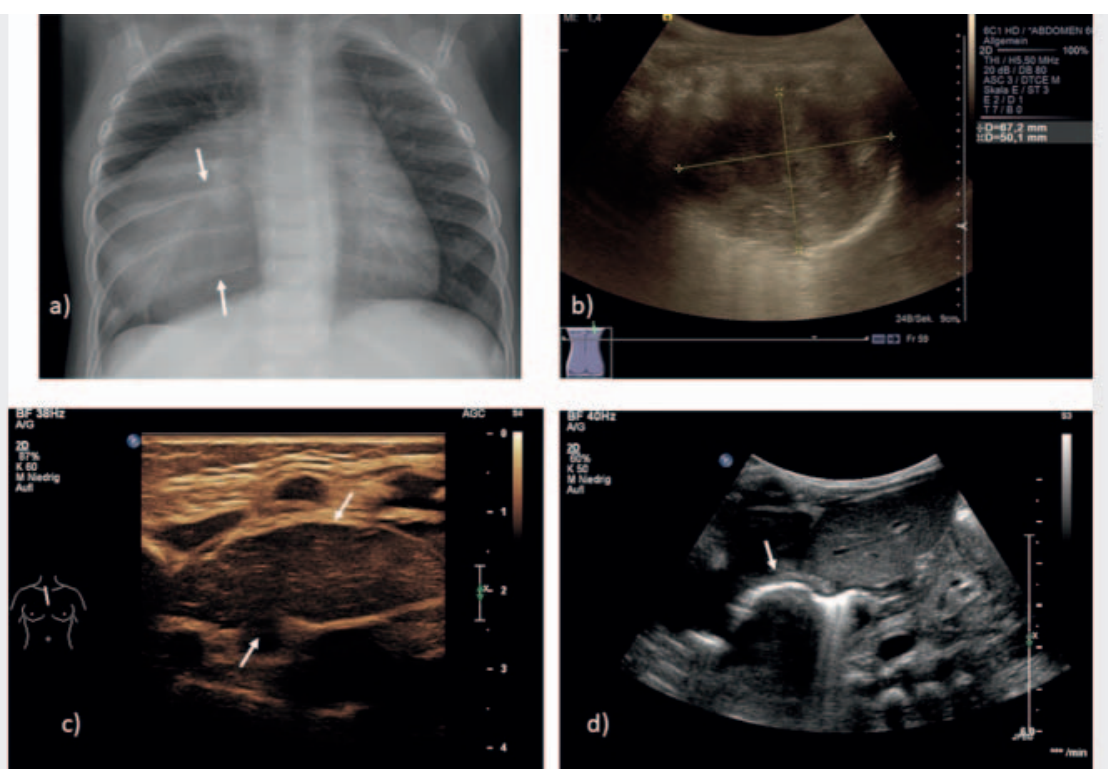

- Fig. 2 a Vast right-sided mediastinal widening in chest X-ray in a 5-year-old child. Additional partial thinning of the dorsal right ribs and widening of the intercostal spaces (arrows), in MRI here infiltration of the intercostal spaces (pictures not shown). b Same child as in 2a, sonographic detection of a large right paravertebral thoracic mass in neuroblastoma arising from the sympathetic trunk. c Inconspicuous thymus (arrows) in an infant, parasternal sagittal plane. $\mathbf{d}$ Hiatal hernia in an infant with recurrent vomiting, supradiaphragmatic evidence of the air-filled herniated portions of the stomach (arrow) in paramedian longitudinal upper abdominal plane.

on color-coded duplex sonography, echogenic reaction of the surrounding mesenteric tissue, and surrounding fluid particularly in the case of local pain on palpation during sonopalpation [3]. Appendicoliths are common even without acute inflammation and should not be given too much importance.
In infants with recurrent vomiting, ultrasound can be used to differentiate between gastroesophageal reflux, hiatal hernia ( $\triangleright$ Fig. 2d), and hypertrophic pyloric stenosis ( $\triangleright$ Fig. 3a). If a patient is vomiting bile, it is difficult to visualize an annular pancreas or duodenal stenosis/membrane. 

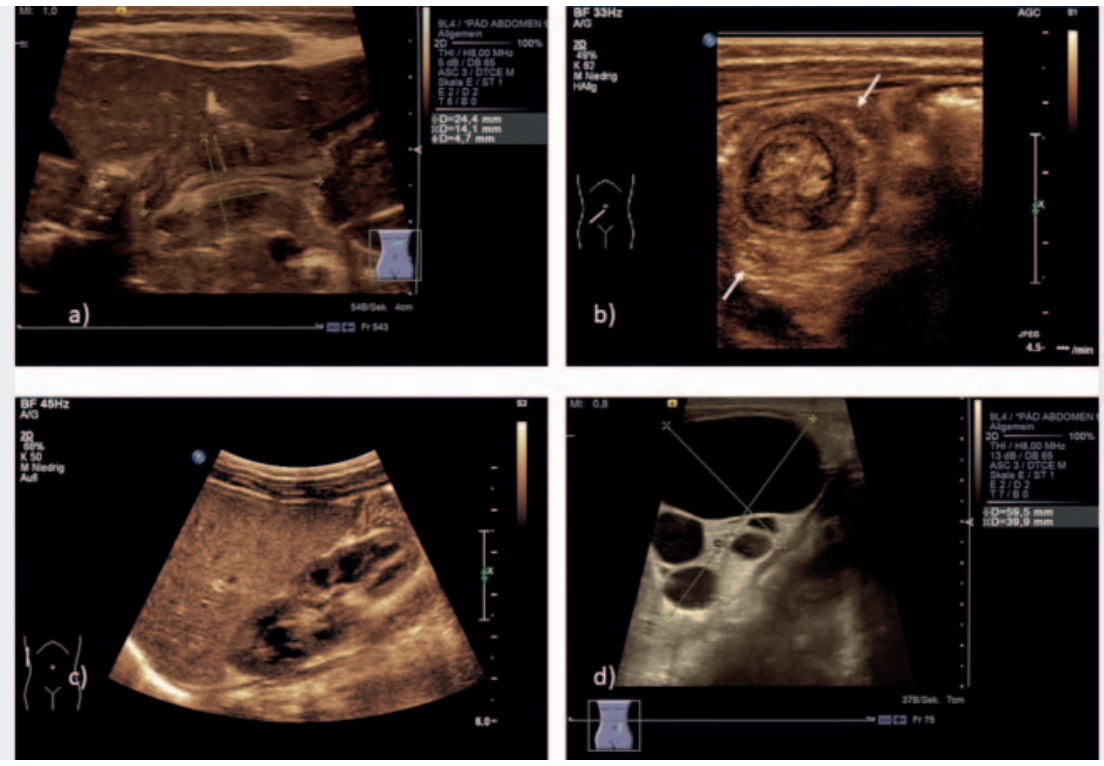

- Fig. 3 a Hypertrophic pyloric stenosis with significantly thickened pyloric wall (measurement of total length, total diameter, and muscle thickness) in an infant with recurrent vomiting and failure to thrive. In the moving image, lack of passage of gastric contents into the empty bulbus duodeni. b lleocolic intussusception (arrows) in a three-year-old child; centrally within the invaginate mesentery and terminal ileum, peripheral wall of the enveloping colon. $\mathbf{c}$ Inconspicuous right kidney in an infant with physiologic renal renculi and markedly hypoechoic medullary pyramids. d Multicystic dysplastic kidney on the left in a newborn. In this case, additional positional anomaly in the left pelvis (see pictogram).

A very specific finding for volvulus in infants and small children with screaming attacks and vomiting is the whirlpool sign [4], which is the result of twisting of the bowel, mesentery, and superior mesenteric vein around the superior mesenteric artery. Colorcoded duplex sonography is useful for visualizing the mesenteric vessels.

A significantly more common differential diagnosis in infants and small children with screaming attacks and vomiting is ileocolic intussusception ( $\mathbf{F i g . 3 b}$ ). This can be reliably diagnosed based on the pathognomonic target sign in the cross section. Intussusception often extends into the transverse colon, sometimes even to the rectum [5]. Hydrostatic reduction of intussusception with warmed Ringer's solution is performed under ultrasound guidance [6].

Gastroenteritis is not an ultrasound indication per se but ultrasound imaging is often requested to rule out other causes of abdominal pain. Thickened bowel walls, fluid-filled bowel loops, hyperperistalsis, and reactive mesenteric lymphadenopathy may be seen.

Renal reniculi (lobulation) is clearly visible on the surface of the kidneys of newborns and infants [7]. The medullary pyramids are significantly more hypoechoic than the cortex and can be confused with cysts or dilated calyces when using lower frequency ultrasound probes ( $\triangleright$ Fig. $3 \mathbf{c}$ ). Urinary tract dilation, parenchymal changes, and cystic renal diseases can be reliably diagnosed on ultrasound.

Unilateral multicystic renal dysplasia is one of the most common congenital renal malformations [8] and is characterized by multiple anechoic cysts of varying size in the nonfunctioning kidney ( $\triangleright$ Fig. $\mathbf{3 d}$ ). The involution rate in multicystic renal dyspla- sia [9] tends to be high so that the disease often can no longer be detected in adults.

Contrast-enhanced voiding urosonography is widely available and established for detecting or ruling out vesicoureteral reflux (VUR). It can be used as an equivalent to conventional voiding cystourethrography for the diagnostic workup of urinary tract dilation [10] or infection [11]. After the bladder is filled with warmed physiological saline solution and contrast agent (SonoVue, Bracco Imaging, approved by the European Drug Commission) via a bladder catheter, the distal ureters and kidneys are alternately displayed in contrast mode to detect low or high pressure VUR ( $>$ Fig. 4a) prior to voiding and during voiding. Voiding urosonography achieves high sensitivity and specificity [12]. A grading system similar to that of voiding cystourethrography is used to classify findings [13]. The urethra can be evaluated with a perineal approach during voiding.

Pathologies of the parenchymatous organs are primarily examined with sonographic imaging. CEUS is increasingly being used off-label in children and adolescents for the diagnostic workup of focal lesions of the abdominal organs (inflammation, trauma, tumor) $[14,15]$. In addition to B-mode imaging, color Doppler, and CEUS, ultrasound elastography can be successfully used in the upper abdomen and can further differentiate diffuse and focal organ pathologies [16].

The most common extracranial tumor in children is the neuroblastoma originating from the adrenal gland or the sympathetic trunk. The most common malignant renal tumor is the nephroblastoma [17]. It is important to reliably differentiate the two tumor entities from one another since the therapeutic approaches differ greatly from one another and preoperative chemotherapy is 

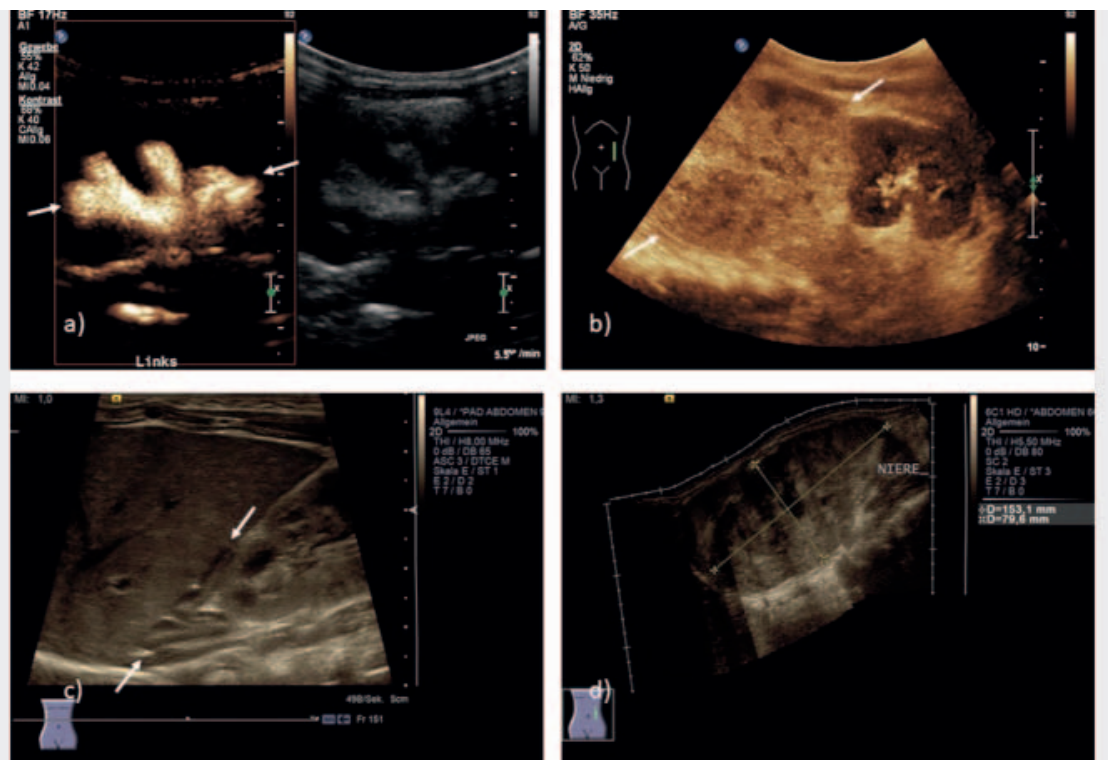

- Fig. 4 a Contrast-enhanced voiding urosonography in an infant, third-degree vesicoureteral reflux of the left kidney (arrows). b Large neuroblastoma originating from the left adrenal gland (arrows) in a three-year-old child, marked displacement of the left kidney caudally with possible infiltration of the upper pole. $\mathbf{c}$ Inconspicuous right adrenal gland (arrows) in a mature newborn. $\mathbf{d}$ Panoramic image of extensive nephroblastoma of the left kidney in a five-year-old child; residual predominantly infiltrated left kidney visible at the caudal pole.

indicated in nephroblastoma based solely on imaging without biopsy ( $>$ Fig. $\mathbf{4 b}, \mathbf{d})$.

The adrenal glands are still physiologically hypertrophic in newborns ( $\triangleright$ Fig. $4 c$ ), with the size decreasing rapidly in the first weeks of life [18]. In neonates, perinatal asphyxia can result in adrenal hemorrhage possibly presenting as a mass [19]. The spontaneous resolution can be monitored by ultrasound.

Ovarian cysts can be very large in the neonatal period resulting in ovarian torsion. Uncomplicated anechoic cysts without solid content are monitored sonographically, while cysts $>5 \mathrm{~cm}$ and hemorrhagic cysts are referred to a pediatric surgeon [20]. In female adolescents with acute lower abdominal pain, ovarian torsion should always be considered as a differential diagnosis. Ovarian torsion is characterized by an enlarged ovary often with a midline position with peripherally displaced follicles and perifocal fluid collection.

In general, the uterus and ovaries are evaluated sonographically in the case of abnormal pubertal development. Using the full bladder as an acoustic window, the uterus and the ovaries are evaluated. In the case of signs of premature puberty, a differentiation is made based on the size of the uterus between the more common isolated premature thelarche (with age-appropriate uterus) and the rare precocious puberty (with enlarged uterus) [21]. The ovaries and uterus have an age-appropriate volume in the case of delayed puberty [22], while the internal sex organs are very small or rudimentary in the case of hypogonadotropic hypogonadism.

In the case of an undescended testicle, ultrasound is used to search for the undescended testicle. If it cannot be found, laparoscopy is required. An inguinal testis can be reliably visualized, while an intraabdominal testis is often difficult to detect [23].
In the case of an acute scrotum, testicular torsion or torsion of the appendix testis must be sonographically ruled out. Colorcoded duplex sonography can be used to evaluate testicular perfusion and afferent and efferent vessels. To exclude torsion, twisting of the vessels ("twisting sign") must be ruled out [24]. Epididymitis/orchitis and incarcerated hernia can be reliably differentiated.

\section{CNS}

Linear and microconvex transducers with the highest possible frequency $(5-20 \mathrm{MHz})$ are used to examine the brain parenchyma, including the basal ganglia, the internal and external CSF spaces, the posterior cranial fossa, and the venous and arterial sinuses, via the large fontanelle (closure between the 9th and 30th month of life [25]) in coronal and (para)sagittal sections. The posterior fontanelle and the temporal fontanelles are used as further acoustic windows ( $\triangleright$ Fig.5a-c) [26]. Lower frequencies are generally needed when performing transcranial sonography of older children.

In infants and small children, sonography can be used to search for skull fracture (e. g., after a fall from the changing table) [27]. A linear transducer is used to search for cephalohematoma, and fracture based on the contusion mark ( $\vee$ Fig. $\mathbf{5 d}$ ). The open, serrated sutures must not be confused with a fracture. In the case of suspected intracranial hemorrhage, ultrasound can be helpful [28]. If the anterior fontanelle is closed, transcranial ultrasound is performed. CMRI should be performed in children with clinical symptoms and CCT in unstable children [29].

Especially in very premature infants, sonographic screening for intraventricular hemorrhage is performed. Intraventricular hemorrhage is caused by the increased vulnerability of the imma- 

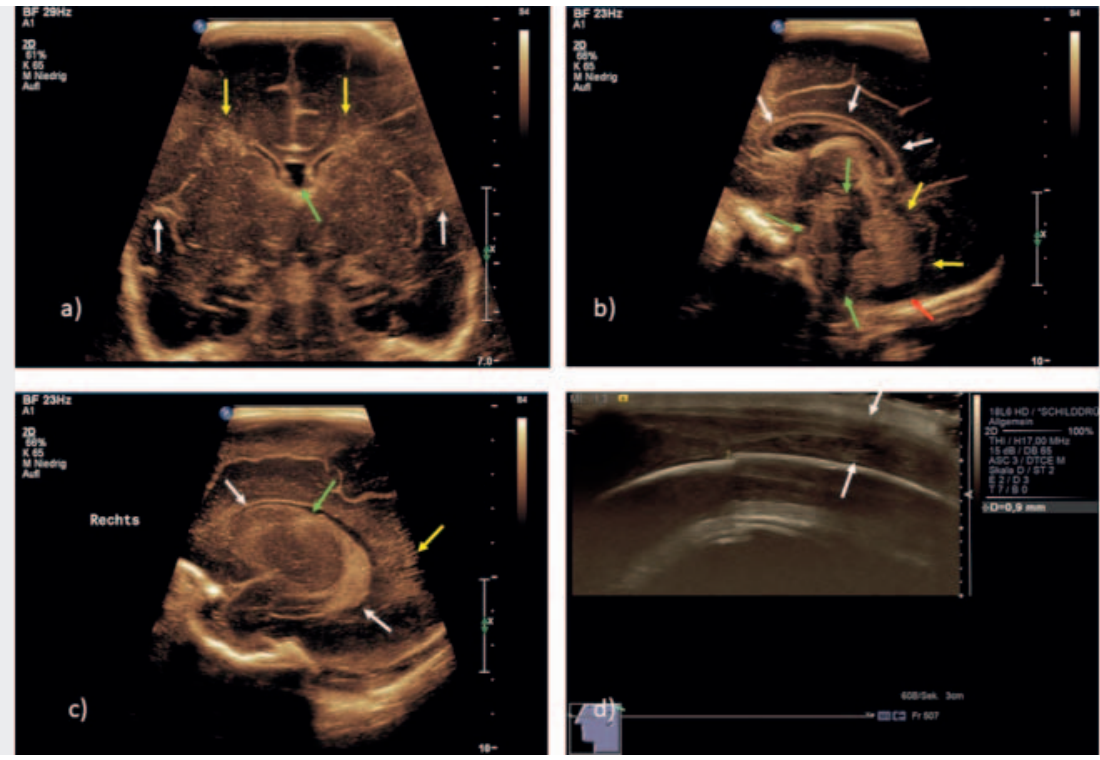

- Fig. 5 a Coronal section through the lateral ventricles and the 3 rd ventricle at the level of the foramina of Monro: Normal findings in a preterm infant with an age of 35 gestational weeks. Showing the basal ganglia, Sylvian fissure (white arrows), cavity of septum pellucidi (green arrow), periventricular echogenicity according to age (yellow arrows), and slightly immature gyration. b Median sagittal section: Normal findings in a preterm infant with an age of 35 gestational weeks showing the corpus callosum (white arrows), brainstem (green arrows), cerebellar vermis (yellow arrows), and cerebellomedullary cistern (red arrow). c Parasagittal section through the right lateral ventricle: Normal findings in a premature infant with an age of 35 gestational weeks showing the slender lateral ventricle with the hyperechoic choroid plexus (white arrows), basal ganglia with caudothalamic groove (green arrow), periventricular echogenicity according to age (yellow arrow). d Presentation of a left parietal skull fracture (offset approx. $1 \mathrm{~mm}$ ) with adjacent big cephalhematoma (arrows) in an infant after a fall from a changing table.

ture subependymal vessels of the germinal matrix located in the caudothalamic groove with respect to hypoxia and fluctuations in blood pressure [30]. Intraventricular hemorrhage is classified according to Papile [31] or DEGUM [32] ( Fig. 6a, c, d). Posthemorrhagic hydrocephalus can develop following extension (of hemorrhage) into the ventricular system. Follow-up ultrasound examinations should be performed. Surgery to place a CSF drain is indicated clinically or based on pathological Doppler ultrasound of the cerebral arteries [33].

In the case of premature infants, a hypoxic-ischemic lesion with hemorrhagic infarction and coagulation necrosis can result in cystic defects in the periventricular white matter (periventricular leukomalacia, PVL) [34]. The initial stage (1-2 weeks) is characterized by an increase in periventricular echogenicity (more hyperechoic than the choroid plexus). Tiny porencephalic cysts that can be missed on MRI form in the second stage (starting at 3 weeks) ( $\triangleright$ Fig. 6 b). In contrast, in the case of hypoxic-ischemic encephalopathy (HIE) in term infants after severe perinatal asphyxia [35], the cerebral cortex, subcortex, and basal ganglia are particularly at risk [36].

Prenatally diagnosed changes, such as malformations, are clarified postnatally using ultrasound and supplementary MRI ( $>$ Fig. 7a, b).

In meningitis in newborns and infants, echogenic deposits in the subarachnoid space or subdural empyema can be seen on ultrasound. Complications like ventriculitis or a rare brain abscess [37] can also be visualized ( $\triangleright$ Fig. 7c).

Doppler ultrasound of the cerebral vessels is often additionally used. For example, it is used to evaluate cerebral perfusion in persistent ductus arteriosus (reduced diastolic flow rate with absence of the Windkessel effect of the aorta) in premature infants, to detect increased intracranial pressure (reduced or negative diastolic flow) in hydrocephalus, and to diagnose territorial ischemia ( $\nabla$ Fig. $\mathbf{7 d}$ ) or sinus thrombosis.

Sonography of the spinal canal can be easily performed in newborns and small infants because the vertebral arches have not yet ossified. The examination is performed in a prone position with high-resolution linear transducers. The entire spinal canal can be scanned on the sagittal plane and the position of the medullary cone can be reliably determined ( $\triangleright$ Fig. 8 a). In the case of a sonographically normal anatomy under good examination conditions, additional imaging is not necessary [38]. Typical reasons for performing a sonographic examination of the spinal canal in neonatology are to rule out a tethered cord or spinal dysraphism, e.g., in Chiari malformation or suspicion of bladder and bowel dysfunction ( $\triangleright$ Fig. 8b). A nuchal scan of the craniocervical junction is performed using a convex transducer ( $\bullet$ Fig. $\mathbf{8 c}$ ).

\section{Soft tissues}

The diagnostic workup of soft tissue swelling often includes ultrasound. High-frequency linear transducers with high spatial resolution are used for this purpose. Enlarged lymph nodes are often the cause of cervical soft tissue swelling. Reactive lymph node enlargement is common and can typically be reliably detected on ultrasound. Reactive lymph node enlargement must be differentiated from lymph node abscesses or malignant lymph node enlargement (e. g., lymphoma) so that histological/microbiological 

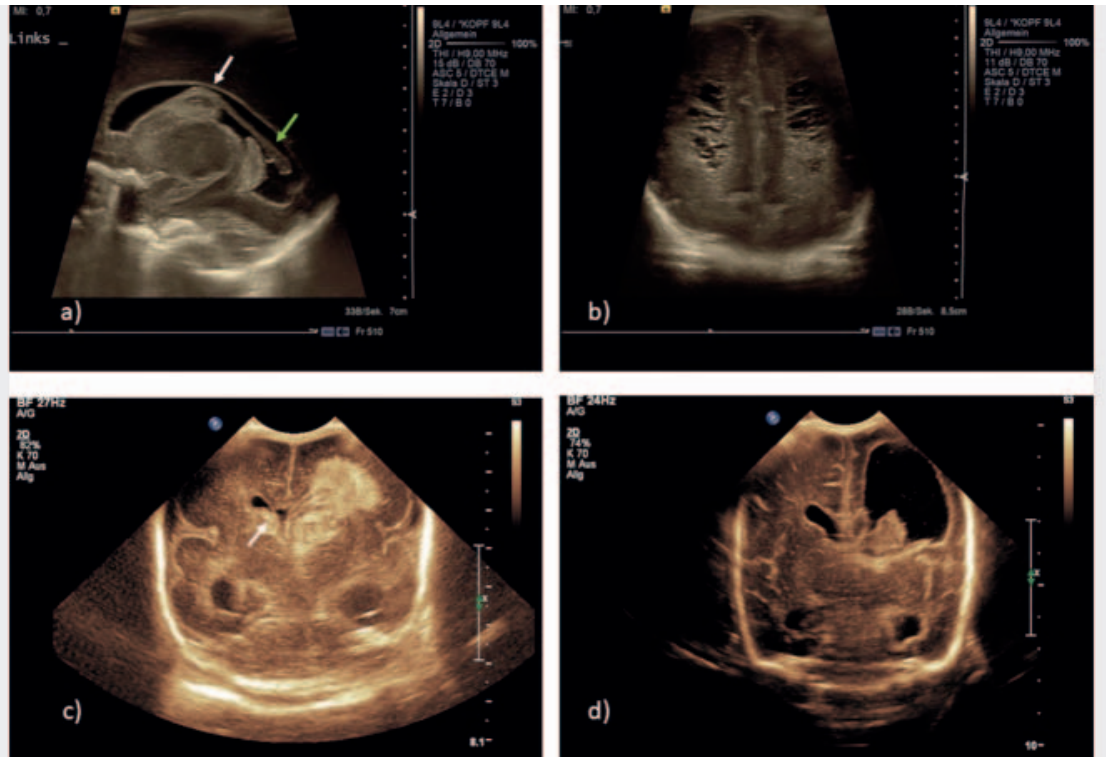

- Fig. 6 a Parasagittal section through the left lateral ventricle in a preterm infant with an age of 24 gestational weeks: showing an echogenic subependymal hemorrhage within the caudothalamic groove (white arrow) and evidence of an intraventricular coagulum (green arrow, adjacent to the choroid plexus) in an intraventricular hemorrhage, less than $50 \%$ of the ventricular lumen filled by the coagulum (intraventricular hemorrha$\mathrm{ge}=\mathrm{IVH}{ }^{\circ} \mathrm{ll}$ according to DEGUM). $\mathbf{b}$ Coronal section through the periventricular medullary bed dorsal to the lateral ventricular posterior horns in a preterm infant with a gestational age of 26 weeks at approximately 5 weeks of age: Multiple partially communicating cystic medullary lesions in the sense of periventricular leukomalacia stage 2. c Coronal section in a premature infant with a gestational age of 25 weeks: Due to a large subependymal hemorrhage in the left caudothalamic groove, compression of the left terminal vein has occurred with secondary hemorrhagic infarction left periventricular, IVH with hemorrhagic infarction of the brain parenchyma (according to DEGUM). Additionally, small subependymal hemorrhage on the right side (arrow). d Same child as in 6c), course after about 12 weeks. Cystic transformation of the infarct area, large porencephalic defect with connection to the left lateral ventricle, showing a residual blood clot therein.
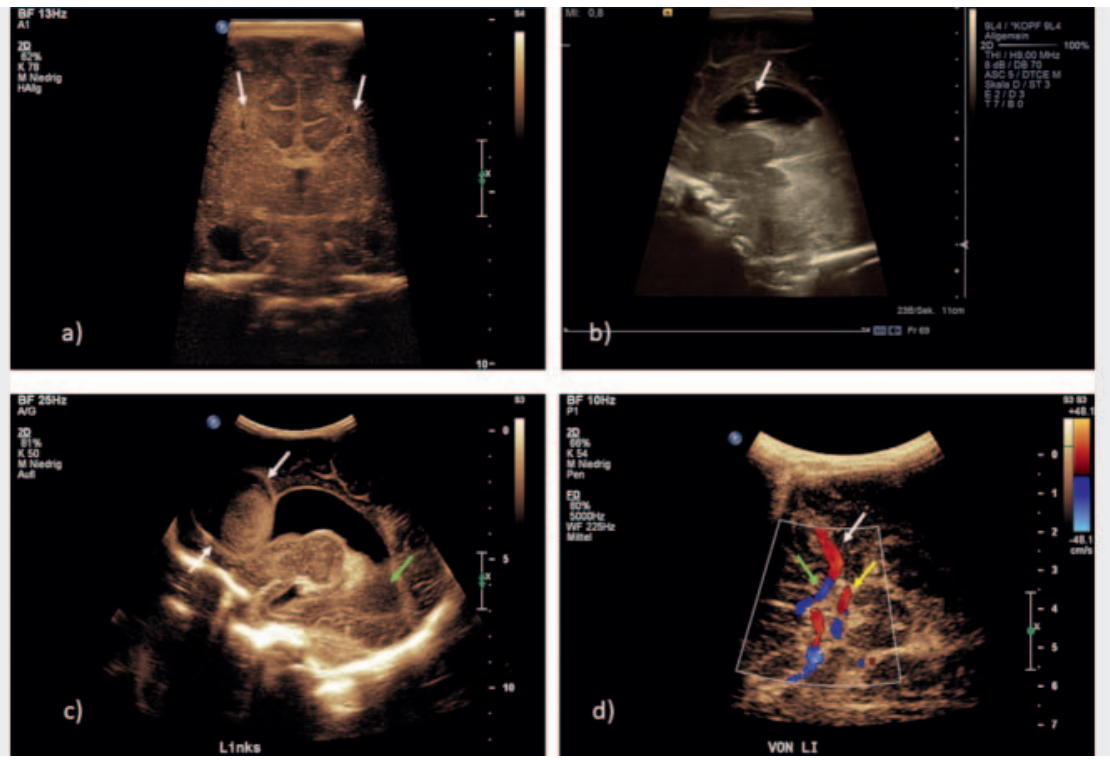

- Fig. 7 a Mature baby with agenesis of the corpus callosum, steer horn configuration of the lateral ventricles (arrows). b Mature newborn with Chiari malformation: In median sagittal section, $4^{\text {th }}$ ventricle and cerebellomedullary cistern not delimitable, thickened massa intermedia. Child already supplied with ventriculoperitoneal shunt (included in the image margin in the midline, arrow). c Large left frontal brain abscess (white arrows) in a mature infant with meningoencephalitis caused by Listeria monocytogenes. In addition, evident internal echoes in the left lateral ventricular posterior horn in the sense of ventriculitis (green arrow). $\mathbf{d}$ Color duplex sonographic normal view of the circulus arteriosus Willisii from transtemporal, in this case from the left side: with M1 segment of the left middle cerebral artery (white arrow), A1 segment of the left anterior cerebral artery (green arrow), and P1 segment of the left posterior cerebral artery (yellow arrow). Beyond the midline, corresponding vessels of the opposite side. Dorsal to the circulus showing the pedunculi cerebri as the leading structure. 


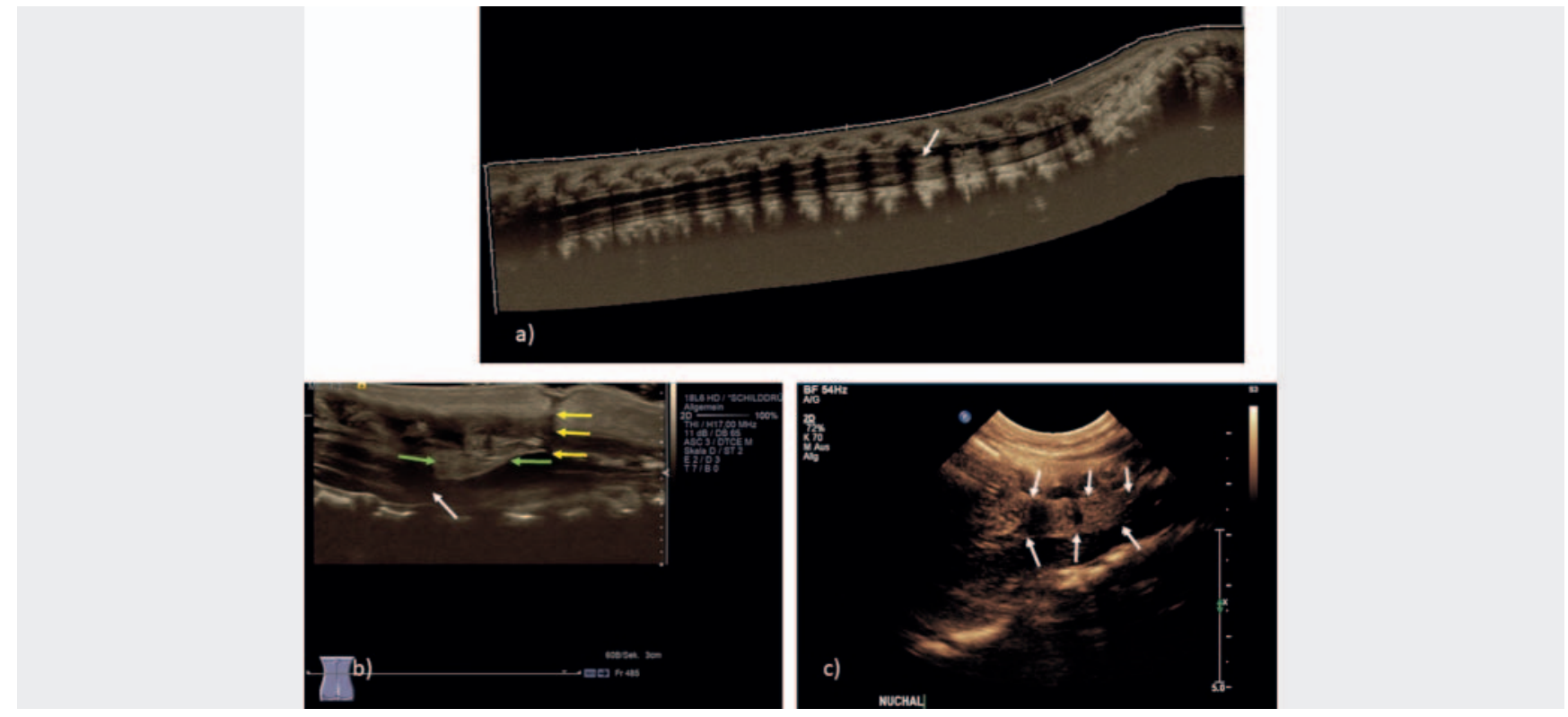

- Fig. 8 a Panoramic view of the spinal canal at the level of the middle to lower thoracic spine, lumbar spine and os sacrum with normal position of the inconspicuous medullary cone (arrow). b Tethered cord syndrome with low position of the medullary cone at the level of the lumbosacral junction (white arrow), additional associated echogenic intraspinal lipoma (green arrows) and sacral dermal sinus (yellow arrows). $\mathbf{c}$ Herniation of the cerebellar tonsils (arrows) into the cervical spinal canal in an infant with Chiari malformation, with the hypoechoic cervical medulla ventrally.

confirmation and appropriate treatment can be initiated in a timely fashion. Reactive lymph nodes have an oval shape (ratio of length to diameter $\geq 2: 1$ ) and a central hilum [39] with a pronounced hilar perfusion pattern in some cases on color-coded duplex sonography. In contrast, lymph node abscesses have blurred margins, a loss of architecture with hypoechoic liquefaction, and an echogenic inflammatory reaction of the surrounding tissue. In less acute cases and in lymph node calcification, an infection with atypical mycobacteria requiring complete surgical removal must be considered [40]. Malignant lymph nodes are often round, highly hypoechoic, and grouped. The architecture is disrupted, a hilum cannot be delimited, and color-coded duplex sonography can show an atypical peripheral vascularization pattern [41].

Further causes of soft tissue swelling include vascular malformation and hemangiomas, which can usually be effectively visualized ( $\triangleright$ Fig. 10a). The internal pattern is determined by the size of the vessels, the degree of thrombosis, and the fat tissue content. High and low flow vascular malformations can be differentiated with color-coded duplex sonography. Cystic lymphatic malformations are anechoic/septated. Internal echoes are often seen after hemorrhage ( $\triangleright$ Fig. 10b).

Cervical soft tissue swelling can also be caused by median or lateral cysts of the neck. These can be confused with solid masses in the case of internal echoes caused by hyperdensity [42]. Thyroid volume and parenchyma can be effectively evaluated on ultrasound. Color-coded duplex sonography can be used to differentiate between acute and chronic thyroiditis or Graves' disease. Thyroid masses are evaluated based on morphology, perfusion, and elastography [43].

\section{Musculoskeletal system}

Sonographic screening of the infant hip according to Graf in order to evaluate hip maturity is performed as part of U3 (part of the German prevention program). Hip dysplasia is the most common congenital deformity of the human skeletal system $(2-5 \%$ in Germany). If untreated, early hip osteoarthritis can develop [44]. Since the introduction of comprehensive screening, significantly fewer orthopedic interventions have been needed in Germany [45]. The examination is highly standardized (correct lateral positioning of the child, scanning method, standard plane setting) $[46,47]$. In the case of a mature hip joint, the not yet ossified hypoechoic femoral head is centered in the already partially ossified acetabulum ( $\triangleright$ Fig.9a). In the case of dysplasia with an insufficient or poorly formed bony acetabulum, the femoral head is decentered to varying degrees ( $\triangleright$ Fig.9b).

Hip joint effusion is often seen in small children with a spontaneous limp, e. g., in transient synovitis. The hip joint is examined sonographically using a ventral approach. In the case of effusion, the joint capsule is raised by anechoic ( $\mathbf{F i g . 1 0} \mathbf{c}$, d) or hyperechoic fluid (e. g., in septic arthritis or hemarthrosis). Sonographic follow-up examinations are performed until the effusion resolves. If the effusion persists, MRI is used for further diagnostic workup [48].

A fracture can be verified sonographically with high sensitivity and specificity [49]. Signs of fracture include disruption of the cortical bone possibly with step formation, formation of a bulge, axial angulation, subperiosteal hematoma, soft-tissue hematoma, and hemarthrosis in the case of joint involvement [50]. Due to limited standardized documentation and clarity for non-examiners, the method is currently only used in a reserved manner. Soft-tissue injuries (hemorrhage, rupture of muscle fiber), inflam- 

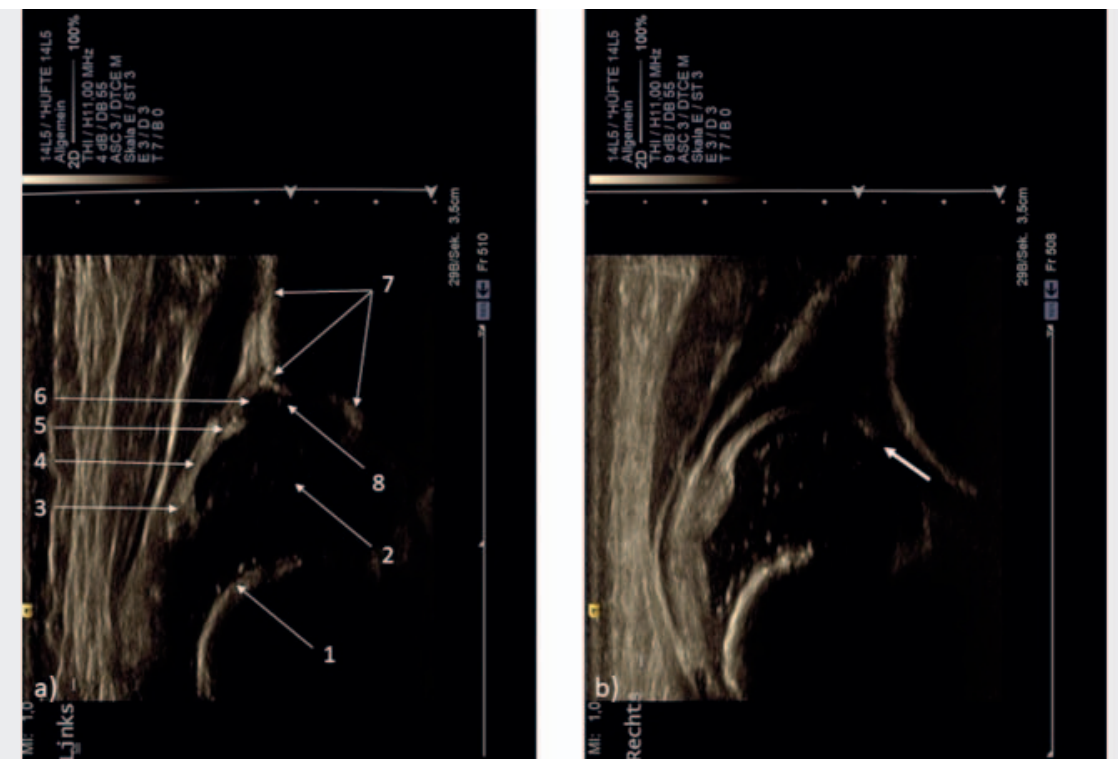

- Fig. 9 a Mature left hip joint (type la according to Graf) in a young infant in the standard plane according to Graf in the recommended "standing position", with marking of the anatomical landmarks. 1: chondrosseous border of the proximal femur. 2: Femoral head (without ossification center). 3: Synovial fold, caudal end of joint capsule next to greater trochanter. 4: Joint capsule. 5: Labrum. 6: Hyaline cartilage acetabular roof. 7: Bony contour of the os ilium incl. lower limb with 8: "turning point". b Decentered right hip joint in a newborn, the femoral head has completely left the poorly formed bony acetabulum, the cartilage acetabular roof is displaced caudally (arrow), hip type IV according to Graf.
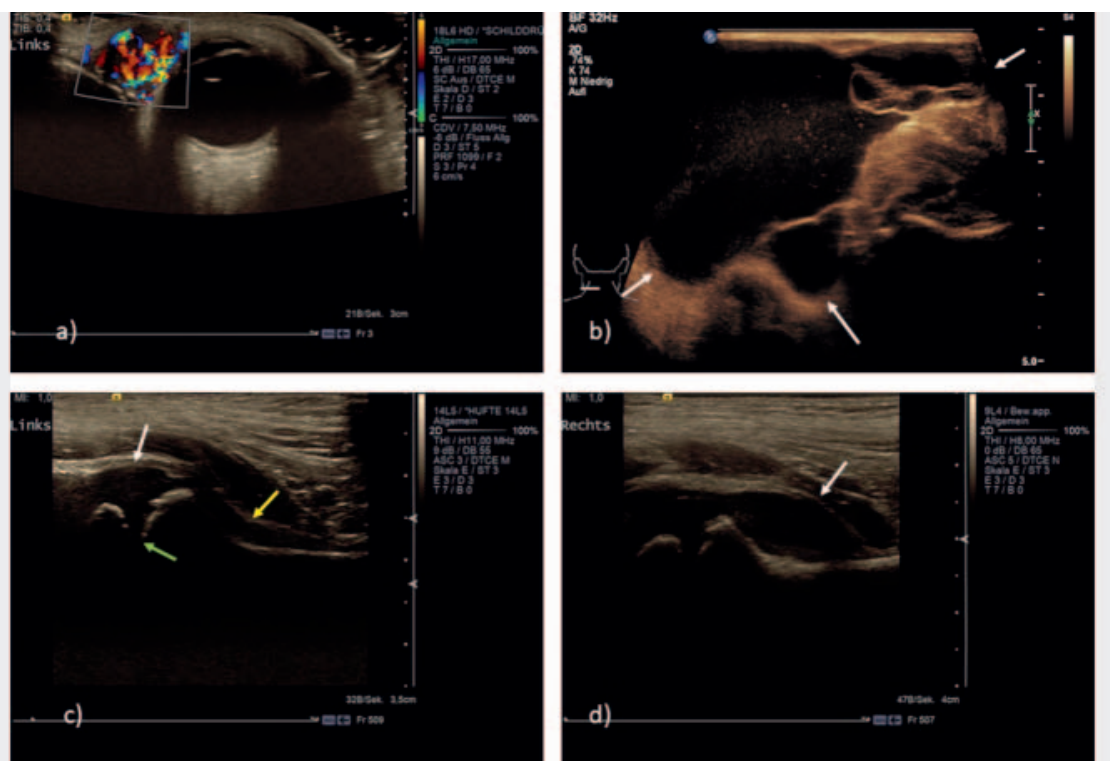

- Fig. 10 a Typical appearance of a hemangioma with pronounced vascularization in color-coded duplex sonography in an infant with a small periorbital mass. b Large lymphatic malformation (white arrows) with a few septations and fluctuating internal echoes in a five-year-old boy with progressive left cervical/nuchal mass. c Normal findings of a hip joint in a toddler: femoral head (white arrow) with clearly visible epiphyseal gap (green arrow), the joint capsule (yellow arrow) follows the concavity along the proximal metadiaphysial junction. $\mathbf{d}$ Anechoic effusion in a toddler with coxitis fugax, marked convex detachment of the joint capsule (arrow) along the proximal metadiaphysial junction.

mation, tumors, and some genetically determined muscular diseases can be evaluated and differentiated sonographically in children and adolescents.

\section{Summary}

Ultrasound in children and adolescents has an extremely broad range of possibilities. In addition to the various uses of ultrasound known from adult medicine, there are numerous additional agespecific possibilities, in particular ultrasound examination of the brain and spinal canal in newborns and infants. In the majority of 
cases, ultrasound is used as the primary imaging modality and often makes additional imaging unnecessary.

Optimal examination conditions for the child and the parents require consideration of the child's needs. The examination should be as short as possible. However, examinations of noncompliant children can take significantly longer than examinations of adults.

Knowledge of the various pediatric disease patterns and good collaboration with pediatric colleagues are essential for ensuring fast and adequate examinations.

\section{Conflict of Interest}

The authors declare that they have no conflict of interest.

\section{References}

[1] Claes AS, Clapuyt P, Menten R et al. Performance of chest ultrasound in pediatric pneumonia. Eur J Radiol 2017; 88: 82-87

[2] Raimondi F, Rodriguez Fanjul J, Aversa S et al. Lung Ultrasound for Diagnosing Pneumothorax in the Critically III Neonate. J Pediatr 2016; 175: 74-78.e1

[3] Vignault F, Filiatrault D, Brandt ML et al. Acute appendicitis in children: evaluation with US. Radiology 1990; 176: 501-504

[4] Patino MO, Munden MM. Utility of the sonographic whirlpool sign in diagnosing midgut volvulus in patients with atypical clinical presentations. J Ultrasound Med 2004; 23: 397-401

[5] Verschelden P, Filiatrault D, Garel L et al. Intussusception in children: reliability of US in diagnosis-a prospective study. Radiology 1992; 184: 741-744

[6] Berthold L, Moritz ]. Interventionelle Eingriffe bei Darmobstruktionen im Kindesalter. In: Mahnken A, Thomas C, Wilhelm K Hrsg. Interventionelle Radiologie. 1. Aufl. Stuttgart: Thieme; 2019

[7] Hricak H, Slovis TL, Callen CW. Neonatal kidneys: sonographic anatomic correlations. Radiology 1983; 147: 699-702

[8] Schreuder MF, Westland R, van Wijk JA. Unilateral multicystic dysplastic kidney: a meta-analysis of observational studies on the incidence, associated urinary tract malformations and the contralateral kidney. Nephrol.Dial.Transplant 2009; 24: 1810-1818

[9] Hains DS, Bates CM, Ingraham S et al. Management and etiology of the unilateral multicystic dysplastic kidney: a review. Pediatr.Nephrol 2009; 24: $233-241$

[10] AWMF-Leitlinien Pädiatrische Radiologie "Harntraktdilatationen bei Kindern - Bildgebende Diagnostik" (April 2020). Im Internet (Stand 22.02.2021): https://www.awmf.org/uploads/tx_szleitlinien/ 064-06I_S1_Harntraktdilation-Kinder_2020-07.pdf

[11] AWMF-Leitlinien Pädiatrische Radiologie "Harnwegsinfektionen bei Kindern - Bildgebende Diagnostik” (April 2020). Im Internet (Stand 22.02.2021): https://www.awmf.org/uploads/tx_szleitlinien/ 064-007I_S1_Harnwegsinfektion_bei_Kindern_2020-07.pdf

[12] Darge K, Beer M, Gordjani N et al. Contrast enhanced voiding urosonography with the use of a 2nd generation US contrast medium: preliminary results. Pediatr Radiol 2004; 34: 97

[13] Darge K, Troeger J. Vesicoureteral reflux grading in contrast-enhanced voiding urosonography. Eur J Radiol 2002; 43: 122-128

[14] Dietrich CF, Nolsøe CP, Barr RG et al. Guidelines and Good Clinical Practice Recommendations for Contrast Enhanced Ultrasound (CEUS) in the Liver - Update 2020 - WFUMB in Cooperation with EFSUMB, AFSUMB, AIUM, and FLAUS. Aktualisierte Leitlinien und Empfehlungen für die gute klinische Praxis für CEUS der Leber. Ultraschall in Med 2020; 41: 562-585

[15] Claudon M, Dietrich CF, Choi BI et al. Guidelines and Good Clinical Practice Recommendations for Contrast Enhanced Ultrasound (CEUS) in the Liver - Update 2012. Ultraschall in Med 2013; 34: 11-29

[16] Mentzel H. Anwendungsmöglichkeiten und Grenzen der Elastografie. In: Deeg K, Hofmann V, Hoyer P Hrsg. Ultraschalldiagnostik in Pädiatrie und Kinderchirurgie. 4. Aufl. Stuttgart: Thieme; 2013

[17] Dumba M, Jawad N, McHugh K. Neuroblastoma and nephroblastoma: a radiological review. Cancer Imaging 2015; 15: 5

[18] Menzel D, Hauffa BP. Changes in size and sonographic characteristics of the adrenal glands during the first year of life and the sonographic diagnosis of adrenal hyperplasia in infants with 21-hydroxylase deficiency. J Clin Ultrasound 1990; 18: 619-625

[19] Koplewitz BZ, Daneman A, Cutz E. Neonatal adrenal congestion: a sonographic-pathologic correlation. Pediatr Radiol 1998; 28: 958-962

[20] Garten L, Schmid O, Degenhardt P. Neonatale Ovarialzysten. Monatsschr Kinderheilkd 2008; 156: 677-682

[21] Haber HP, Wollmann HA, Ranke MB. Pelvic ultrasonografy: early differentiation between isolated premature thelarche and central precocious puberty. Eur J Pediatr 1995; 154: 182-186

[22] Soules MR. Adolescent amenorrhoe. Pediatr Clin North Am 1987; 34 : 1083-1103

[23] Tasian GE, Copp HL, Baskin LS. Diagnostic imaging in cryptorchidism: utility, indications, and effectiveness. J. Pediatr. Surg 2011; 46: 2406-2413

[24] Gunther P, Schenk JP, Wunsch R. Acute testicular torsion in children: the role of sonography in the diagnostic workup. Eur Radiol 2006; 16: 25272532

[25] Richardson JD, Grant EG. Scanning Techniques and normal Anatomy. In: Grant EG ed;. Neurosonography of the Pre-Term Neonate. Berlin: Springer; 1986: 1-24

[26] DEGUM Dokumentationsleitlinie "Standarddokumentation der Sonografie des kindlichen Neurokraniums". Im Internet (Stand 22.02.2021): https://www.degum.de/fileadmin/dokumente/sektionen/paediatrie/ dokumentationsempfehlungen/P_08_Poster_SCh_del_Dokumenta tionsempfehlung_Sch_del_Poster_.pdf

[27] Parri N, Crosby B], Mills L et al. Point-of-Care Ultrasound for the Diagnosis of Skull Fractures in Children Younger Than Two Years of Age. J Pediatr 2018; 196: 230-236.e2

[28] Masaeli M, Chahardoli M, Azizi S et al. Point of Care Ultrasound in Detection of Brain Hemorrhage and Skull Fracture Following Pediatric Head Trauma; a Diagnostic Accuracy Study. Arch Acad Emerg Med 2019; 7: e53

[29] Lehner M, Deininger S, Wendling-Keim D. Management des SchädelHirn-Traumas im Kindesalter. Monatsschr Kinderheilkd 2019; 167: 9941008

[30] Volpe J]. Brain injury in the premature infant: overview of clinical aspects, neuropathology, and pathogenesis. Semin Pediatr Neurol 1998; 3: $135-151$

[31] Papile LA, Burstein J, Burstein R et al. Incidence and evaluation of subependymal intraventricular hemorrhage: a study of infants with birth weights less than 1500 gramms. J Pediatr 1978; 92: 529-534

[32] Deeg KH, Staudt F, von Rohden L. Klassifikation der intrakraniellen Blutungen des Frühgeborenen. Ultraschall in Med 1999; 20: 165-170

[33] Deeg KH. Sonographic and Doppler Sonographic Diagnosis of Posthemorrhagic Hydrocephalus. Ultraschall in Med 2015; 36: 318-336

[34] Townsend SF, Rumack CM, Thilo EH et al. Late neurosonographic screening is important to the diagnosis of periventricular leukomalacia and ventricular enlargement in preterm infants. Pediatr Radiol 1999; 29: 347-352

[35] Volpe J]. Neurology of the Newborn. 5th ed. Philadelphia: Saunders; 2008

[36] Brun A, Kyllerman M. Clinical, pathogenetic and neuropathological correlates in dystonic cerebral palsy. Eur J Pediatr 1979: 131 
[37] Renier D, Flandin C, Hirsch E et al. Brain abscesses in neonates. J Neurosurg 1988; 69: 877-882

[38] Rohrschneider WK, Forsting M, Darge K et al. Diagnostic value of spinal US: comparative study with MR imaging in pediatric patients. Radiology 1996; 200: 383-388

[39] Rettenbacher T. Sonografie der peripheren Lymphknoten Teil 1: Normalbefunde und B-Bild-Kriterien. Ultraschall in Med 2010; 31: 344-362

[40] Schoenfeld N, Haas W, Richter E et al. Recommendations of the German Central Committee against Tuberculosis (DZK) and the German Respiratory Society (DGP) for the Diagnosis and Treatment of Non-tuberculous Mycobacterioses. Pneumologie 2016; 70: 250-276

[41] Rettenbacher T. Sonografie der peripheren Lymphknoten Teil 2: DopplerKriterien und typische Befunde bestimmter Entitäten. Ultraschall in Med 2014; 35: 10-32

[42] Ahuja AT, King AD, Metreweli C. Sonographic evaluation of thyroglossal duct cyst in children. Clin Radiol 2000; 55: 770-774

[43] Tritou I et al. Pediatric thyroid ultrasound: a radiologist's checklist. Pediatr Radiol 2020; 50: 563-574

[44] Jacobsen S, Sonne-Holm S et al. Hip dysplasia and osteoarthrosis. Acta Orthopaedica 2005; 76: 149-158

[45] Wirth T, Stratmann L, Hinrichs F. Evolution of late presenting developmental dysplasia of the hip and associated surgical procedures after
14 years of neonatal ultrasound screening. J Bone Joint Surg $\mathrm{Br} 2004 ; 86$ : 585-589

[46] Graf R, Baumgartner F, Lercher K. Ultraschalldiagnostik der Säuglingshüfte. 2. Aufl. Berlin: Springer; 2012

[47] DEGUM Dokumentationsleitlinie "Standarddokumentation der Sonografie der Neugeborenen- und Säuglingshüfte”. Im Internet (Stand 22.02.21): https://www.degum.de/fileadmin/dokumente/sektionen/paediatrie/ dokumentationsempfehlungen/S\%C3\%A4uglingsh\%C3\%BCfte.pdf

[48] AWMF-Leitlinien "Muskuloskelettale Schmerzen bei Kindern und Jugendlichen - Ein Algorithmus zur differenzialdiagnostischen Abklärung eines häufigen Leitsymptoms in der Kinder- und Jugendmedizin" (November 2020). Im Internet (Stand 22.02.2021): https://www.awmf.org/uploads/ tx_szleitlinien/027-073m_S2k_Muskuloskelettale-Schmerzen-KinderJugendliche\%E2\%80\%93Algorithmus_2020-12.pdf

[49] Moritz JD, Berthold LD, Soenksen SF et al. Ultrasound in diagnosis of fractures in children: unnecessary harassment or useful addition to X-ray? Ultraschall in Med 2008; 29: 267-274

[50] Katzer C, Wasem ], Eckert K et al. Ultrasound in the Diagnostics of Metaphyseal Forearm Fractures in Children: A Systematic Review and Cost Calculation. Pediatr Emerg Care 2016; 32: 401-407 